\title{
Pratica interdisciplinar em disciplina de projeto de produto com ênfase na inovação e na tecnologia
}

Interdisciplinary practice in the discipline of product design with an emphasis on innovation and technology

\author{
> Ana Veronica Pazmino \\ UFSC, Brasil \\ ana.veronica@ufsc.br \\ > RegianeTrevisanPupo \\ UFSC, Brasil \\ regiane.pupo@ufsc.br
}

\author{
> Rodrigo Braga \\ UFSC, Brasil \\ rodrigo.braga@ufsc.br
}

\begin{abstract}
This paper shows the pedagogical structure for facilitating the inter-relationship of the disciplines of design and innovation, smart design and materialization through which students developed interactive products with the appropriation and application of knowledge of programming, rapid prototyping and innovation through technology. This work presents the results of an interdisciplinary practice in the design course at the Federal University of Santa Catarina in the discipline of design with emphasis on innovation and technology. The results are qualitative in relation to students learning and recommendations for interdisciplinary pedagogy in design courses.
\end{abstract}

Keywords: Interdisciplinary, Smart Design, Innovation, Technology, Materialization

\section{Introdução}

O processo de ensino e aprendizagem no âmbito universitário exige que os professores realizem práticas de interconexão entre diversos saberes. Este artigo mostra uma ação pedagógica interdisciplinar e os resultados da prática projetual.Para isto o trabalho apresenta como objetivo geral, aplicar a interdisciplinaridade como açáo pedagógica para que os alunos possam desenvolver produtos interativos, os objetivos específicos foram:

1. Relacionar saberes de programação, materializaçáo e design;

2. Desenvolver o conhecimento tácito;

3. Trabalhar com a materializaçáo digital de modelos ao longo do processo projetual;

4. Aplicar conhecimentos de programação;

5. Produzir modelos interativos;

A partir das aulas teóricas e práticas e dos produtos interativos desenvolvidos pelos alunos são mostrados os resultados da prática interdisciplinar. O trabalho mostra uma reflexão sobre a importância do planejamento e estruturaçáo de uma disciplina de projeto com três professores de áreas diversas de conhecimento. A percepção do aluno como receptor destes conhecimentos e do processo de ensino e aprendizagem em um âmbito diverso ao tradicional processo de ensino de design na academia. $\mathrm{O}$ trabalho reforça que os diversos saberes traduzidos e explicados de forma adequada são formas que possibilitam o exercício da multidisciplinaridade e a compreensão da complexidade do processo de design.

\section{Projeto Pedagógico}

Segundo o Projeto Pedagógico do Curso de Design (2011) “O curso de Design do EGR/CCE/UFSC foi pensado em uma estrutura organizacional livre entre as formaçóes, na qual as disciplinas de Projeto devem ser as norteadoras da formação dos acadêmicos. As disciplinas de projeto não terão "vida" isolada e apenas serão cursadas em conjunto com mais três disciplinas em requisito paralelo (Figura. 1). Essas disciplinas de requisito paralelo darão sustentação ao projeto e seus três docentes serão os responsáveis pelo funcionamento, gerenciamento e atribuição de avaliação do projeto realizado pelo aluno, que deve conter informação de todas elas para um completo entendimento do curso".

Segundo o Projeto Pedagógico os docentes das disciplinas de requisito paralelo e, por conseguinte docentes do projeto em que estão ligadas, devem estruturar seus conteúdos e cronograma para atingir o melhor resultado de interdisciplinaridade e aprendizado para o aluno, podendo organizar o tempo do semestre de acordo com asnecessidades do conjunto. Porém devem também se preocupar com as demais disciplinas que o aluno realiza concomitantemente para que os trabalhos sejam sempre realizados com a melhor qualidade possível. 


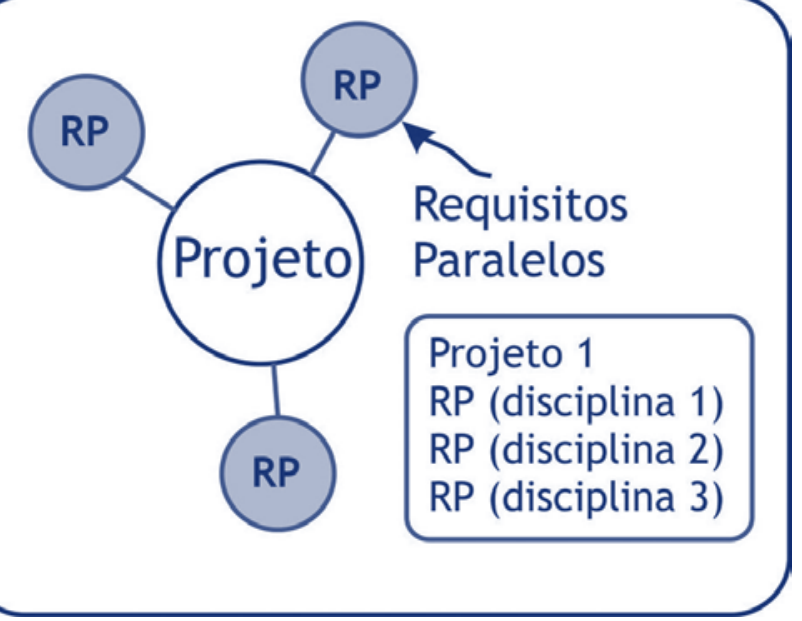

Figura 1: Exemplo de grupo de disciplinas de projeto

Cabe salientar que o Projeto Pedagógico de 2011 iniciou com 14 módulos de projeto para três habilitações (produto, gráfico e animação), atualmente há 23 módulos de projeto que incluem projetos de design de interiores e moda.

\section{Disciplina de Projeto de Produto 16}

As disciplinas de projeto no curso são identificadas por um numero. Os 14 módulos de projeto foram criados em 2011 pelos professores que organizaram o curso.

Em 2012 o módulo de projeto 16 com ênfase na inovação e na tecnologia foi introduzida por iniciativa de três professores que sentiram a necessidade de uma abordagem tecnológica no curso. Dessa forma, a disciplina emerge numa visão interdisciplinar da ação e interaçáo dos professores onde tudo foi negociado e renegociado, estabelecendo-se um processo relacional dos professores envolvidos e de suas áreas de saber. A (Figura 2) mostra a estrutura da disciplina de projeto e suas disciplinas inter-relacionadas.

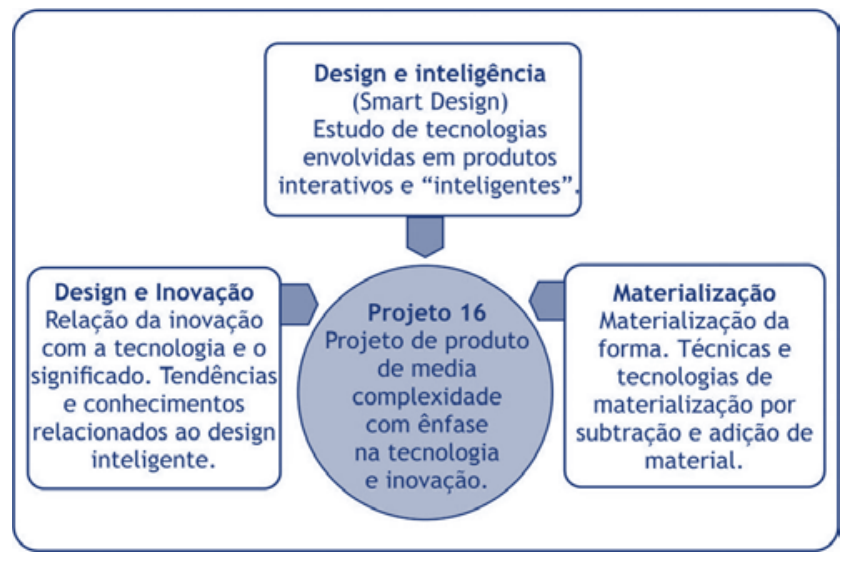

Figura 2: Estrutura do módulo de Projeto 16 e suas disciplinas inter-relacionadas.
A partir da estruturação da disciplina foram estabelecidos vários métodos para alcançar os objetivos específicos. A seguir são mostrados os objetivos e os métodos trabalhados.

1. Relacionar saberes de programação, materialização e design na disciplina de projeto de produto. Os planos de ensino das quatro disciplinas dos três professores envolvidos foram estruturados de forma que os 18 encontros durante o semestre tivessem conteúdos que permitissem as conexôes cognitivas dos alunos;

2. Desenvolver o conhecimento tácito nos alunos. Por meio de estratégias de ensinagem como aulas expositivas dialogadas e as práticas de programação e materialização buscaram desenvolver o conhecimento tácito que segundo (LINS, 2003) pode ser visto como um composto de experiências condensadas, princípios, atitudes, comportamentos, informação contextual, experiência e insight experimentado.

3. Trabalhar com a materializaçáo digital de modelos ao longo do processo projetual. Por meio da construçáo de modelos com diversas técnicas de materialização e acabamentos de várias fidelidades (baixa, média e alta).

4. Aplicar conhecimentos de programação. Aulas práticas de tecnologias que permitam a interação (robótica, programação, automação).

5. Produzir modelos interativos. Aulas práticas iterativas de construção de protótipos funcionais, programação, testes e redesign.

A turma do módulo de projeto teve 10 alunos que formaram 4 equipes: (duas com três integrantes e duas com dois integrantes). Foram desenvolvidos 4 projetos. Neste artigo serão mostrados três, já que um deles está em processo de patente e náo pode ser divulgado devido ao sigilo do processo. O processo de desenvolvimento do projeto adotado incluía as fases de Análise, Síntese, Criatividade e Materialização de forma iterativa, não linear e dinâmica no sentido de troca continua de informaçóes entre as diversas disciplinas inter-relacionadas.

$\mathrm{Na}$ fase de análise as equipes aplicaram diversas ferramentas segundo Pazmino (2013): Análise Diacrônica, Análise Sincrônica, Pesquisa etnográfica junto ao público-alvo (questionários, entrevistas, observaçóes), personas, cenários, painéis semânticos, análise estrutural e funcional de produtos concorrentes e similares. $\mathrm{Na}$ fase de síntese aplicaram a ferramenta de requisitos de projeto incluindo requisitos de materialização e programação. $\mathrm{Na}$ fase de criatividade diversas técnicas criativas de acordo com as habilidades e experiências de cada equipe. E na fase materialização testes com tecnologias de subtração e adição de material. Na disciplina de projeto os três professores estavam juntos de forma a sanar dúvidas em relaçáo a cada área do saber. A (Figura 3) mostra osprodutosdesenvolvidos. 

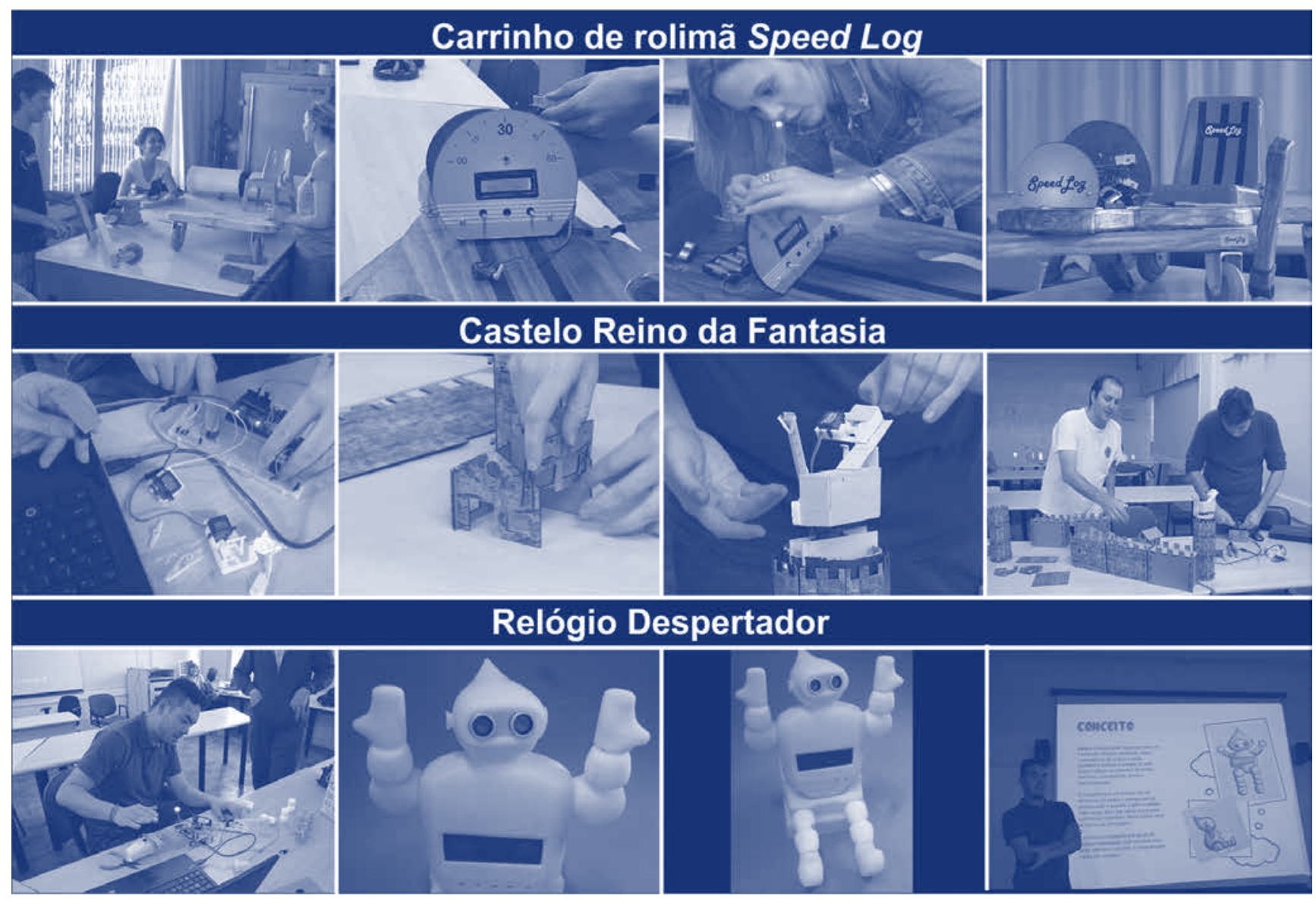

Figura 3: Produtos desenvolvidos

O carrinho de rolimã é um produto inspirado em brincadeira em grupo e ao ar livre. Os requisitos do projeto foram: interativo-responsivo o usuário poderia ver o registro de velocidade e filmar suas açóes, estilo retrô, material madeira, display, suportar até $70 \mathrm{~kg}$. A (Figura 3) mostra a equipe montando o protótipo e realizando as conexóes elétricas do painel. $\mathrm{O}$ carrinho de rolimã combina o resgate de valores antigos, focado no tema retrô, com a tecnologia atual. A proposta envolve liberdade e socializaçáo para a nova geração, por meio daum brinquedo para o público infantil, com abordagem na inovação e tecnologia.

O produto desenvolvido pela segunda equipe foi o brinquedo Reino da Fantasia. Os requisitos do projeto foram: modularidade, material madeira, permitir a interação por meio de açóes de sensores de reconhecimento de presença do inimigo e ataque de catapulta programada. A criança podia montar o castelo em diversas composiçóes. A (Figura 3) mostra os alunos testando a catapulta e montando o castelo.

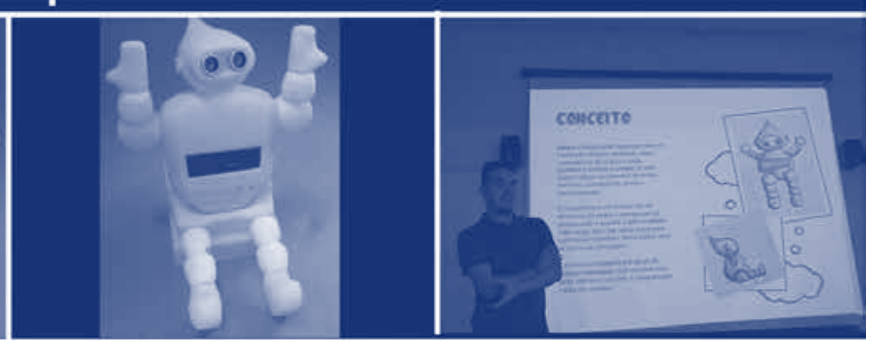

O terceiro produto é o relógio despertador, os requisitos do produto foram: ser interativo - responsivo, modular com encaixes para montar, estilo jovem, material ABS para ser impresso em impressora 3D, possuir som, movimentos simples utilizando o sistema Arduíno e a programação que permita mover o boneco de deitado para sentado, mostrar a hora e ascender a luz dos olhos.

O Quarto produto desenvolvido foi um instrumento musical que não é apresentado neste trabalho já que está em processo de patente.

Cabe salientar que todos os projetos atenderam o enunciado do módulo do projeto 16: Desenvolver um brinquedo modular inteligente. Possuir um sistema eletroeletrônico que permita com que execute funçóes. Possuir uma fonte de energia. Circuito elétrico ou eletrônico (motor, caixa de som, processador, memória, tela, monitor etc.). Os brinquedos podiam atender diversas funçóes, divertir, educar, ensinar entre outras. Devia ter um design em que a inovação fosse percebida não apenas pela tecnologia, mas também pelo significado. A tabela 1 mostra o resultado qualitativo do módulo de projeto relacionando os alunos envolvidos nos 
projetos com os objetivos específicos da disciplina mencionados na introdução do artigo.

Tabela 1: Avaliação dos estudantes/projetos do módulo de projeto.

\begin{tabular}{|c|c|c|c|c|c|c|}
\hline \multirow{2}{*}{$\begin{array}{l}\text { Equipe/ } \\
\text { Projeto }\end{array}$} & \multicolumn{5}{|c|}{ Objetivos especificos da disciplina } & \multirow{2}{*}{ Média } \\
\hline & 1 & 2 & $\exists$ & 4 & 5 & \\
\hline Carrinho & 8 & 10 & 10 & 8 & 8 & 8,8 \\
\hline Castelo & 10 & 10 & 10 & 10 & 8 & 9,6 \\
\hline $\begin{array}{l}\text { Relógio } \\
\text { despertador }\end{array}$ & 7 & 8 & 10 & 8 & 8 & 8,2 \\
\hline $\begin{array}{l}\text { Instrumento } \\
\text { musical }\end{array}$ & 10 & 10 & 10 & 10 & 10 & 10 \\
\hline
\end{tabular}

A média dos alunos ficou em 9,15 que representa terem alcançado os objetivos da disciplina. Deve-se salientar que as equipes que trabalharam melhor em grupo foram as que tiveram melhores rendimentos.

\section{Interdisciplinaridade}

O Módulo de Projeto 16 foi estruturado sabendo que o designer precisa aprender a investigar, dominar as diferentes formas de acesso à informação, desenvolver a capacidade crítica de avaliar, reunir, organizar a informação, sintetizar os requisitos de projeto para que o processo criativo seja eficiente e o produto final satisfaça as necessidades do público alvo.

O currículo de um curso de design dentro da visão interdisciplinar deve ser claro, aberto, interpretativo, flexível, mantendo transaçôes entre os conteúdos na matriz curricular, as disciplinas e os professores. Nada deveria ser criado e determinado previamente, tudo deve ser negociado, renegociado, estabelecendo-se um processo relacional do sujeito consigo mesmo, com os outros e com a realidade. (TRONCA, 2006, p. 77) sustenta que para transitar num currículo interdisciplinar, o educador precisa ser capaz de explorar diversas visóes e alternativas, aceitar a indeterminação e a complexidade. Esse educador deve compreender a complexidade envolvida na tomada de decisão [...]; ser pesquisador por excelência e pouco transmissor de conteúdos; adaptar as propostas curriculares às condiçóes intelectuais e emocionais de seus alunos ao contexto onde vivem.

Saindo de encontro ao mencionado por (TRONCA, 2006) o módulo de Projeto 16 foi estruturado a partir das tendências atuais onde a tecnologia está inserida na vida das pessoas nos mais diversos ambientes. Dessa forma, é fundamental inserir a tecnologia e programaçáo no processo projetual, o fator da inovaçáo e o uso de prototipagem ao longo do processo para testar e melhorar o desenvolvimento de produtos.

Este trabalho defende que o design, como disciplina fica defasado caso não se renove com conceitos novos, forjados a partir dos seus modelos de base ou emprestados de outras disciplinas. Assim, ele precisa se aproximar das fronteiras de outras disciplinas, estabelecer diálogos pluri e multidisciplinares, intercambiando modelos, métodos e conceitos, e criando novas disciplinas.
A interdisciplinaridade tem surgido como uma nova atitude frente ao saber. Ela reconhece as disciplinas, mas promove, num exercício coletivo de saberes (integração possibilitada pela continua intercomunicação). Para Fazenda (1996, p. 31) [...] a interdisciplinaridade representa a orquestração intrínseca das disciplinas, fazendo convergir seus pontos diversificados de origem. [...] seu princípio é sempre o mesmo: caracteriza-se pela intensidade das trocas entre especialistas e pela integração das disciplinas.

Para Fazenda (1979, p. 8) "a interdisciplinaridade antes que um "slogan" é uma relaçáo de reciprocidade, de mutualidade, que pressupóe uma atitude diferente a ser assumida frente ao problema do conhecimento, ou seja, é a substituição de uma concepçâo fragmentária para unitária do ser humano". Para a autora, uma condição de efetivação da interdisciplinaridade é o desenvolvimento da sensibilidade sendo necessário um treino na arte de entender respeitar o outro e somar os conhecimentos.

A integração não deve ser vista como fusão de conteúdos ou métodos, mas, como uma integraçáo de conhecimento visando novos questionamentos, novas buscas, almejando a transformaçâo da própria realidade.

Não se pode separar a interdisciplinaridade dos indivíduos que a praticam e aplicam, o sucesso do módulo de projeto como açáo interdisciplinar se deu pela diversidade de conhecimentos dos professores envolvidos, como pode ser visto a seguir em um pequeno resumo de suas competências.

\section{Integrantes do Módulo de Projeto 16}

Prof. Rodrigo Antonio Marques Braga

Formação: Engenheiro de Controle e Automação, Doutor em Engenharia Informática.

Resumo curriculum vitae: graduação em Engenharia de Controle e Automação pela Pontifícia Universidade Católica do Rio Grande do Sul - PUCRS (1998), mestrado em Engenharia Elétrica pela Pontifícia Universidade Católica do Rio Grande do Sul - PUCRS (2001) e doutorado em Engenharia Informática pela Faculdade de Engenharia da Universidade do Porto - FEUP (2010). Tem experiência na área de Desenho Industrial, Representação Gráfica Espacial, CAD/CAM/CAE, Automação, Controle, Robótica, Inteligência Artificial.

Profa. Regiane Trevisan Pupo

Formação: Arquitetura e Urbanismo, Doutora em Engenharia Civil e pós-doutorado em Arquitetura e Urbanismo

Resumo curriculum vitae: graduação em Arquitetura e Urbanismo pela PUCCAMP - Pontifícia Universidade Católica de Campinas (1986), mestrado em Engenharia de Produção pela UFSC - Universidade Federal de Santa Catarina (2002), doutorado pelo Programa de Pós Graduação da FEC - Faculdade de Engenharia, Arquitetura e Urbanismo da UNICAMP - Universidade Estadual de Campinas e pós-doutorado na FEC/UNICAMP desenvolvendo pesquisa em prototipagem rápida, digitalização $3 \mathrm{D}$ e fabricação digital para arquitetura. Atuando principalmente nos seguintes temas: CAD, computational design, prototipagem rápida e fabricação digital para design e arquitetura. 
Profa. Ana Veronica Pazmino

Formação: Desenho Industrial, Doutorado em Design.

Resumo curriculum vitae: graduação em Desenho Industrial pela Universidade Federal do Rio de Janeiro (1993); Mestrado em Engenharia de Produçáo pela Universidade Federal de Santa Catarina (1999); Doutorado em Design pela PUC-RJ (2010). Tem experiência na área de design de produto, e em Métodos de Projeto, atuando principalmente nos seguintes temas: Metodologia de projeto de produto, design de produto e ecodesign.

\section{Resultados}

Os resultados alcançados na prática interdisciplinar foram quatro projetos interativos desenvolvidos pelos alunos, e a avaliação quantitativa e qualitativa de aprendizagem dos alunos o que demonstra a vocação do design para a interdisciplinaridade e que se apresentam como facilitadores para enfrentar a incerteza e encontrar os meios que permitam o designer navegar num processo complexo e alcançar a inovação. Isto exige uma nova didática, a do aprender a aprender, ou do saber pensar, ou da reflexão-na-ação, buscando a apropriaçáo do conhecimento disponível e seu manejo criativo e crítico. Para Tronca (2006, p. 76) considerando o mundo em constante transitoriedade, onde o conhecimento evolui de forma incontrolável e a quantidade de novas informaçóes disponíveis é cada vez maior, é impossível que maneiras reducionistas de aprendizagem persistam.

A atividade projetual da açáo do projeto foi totalmente iterativa, ou seja, projeto, programação e materialização acontecendo ao mesmo tempo com a mudança de pensamento do educando para a reflexão-na-ação. Os alunos percebiam que deviam inserir os conhecimentos de programação e materialização durante o processo criativo, não separando nem postergando a materializaçáo para o final do processo de desenvolvimento. A eficiência da açáo projetual iterativa permitiu que os alunos pudessem otimizar as decisóes e cumprir com o prazo de entrega.

Conclui-se que cabe aos professores organizar relaçóes interdisciplinares na academia para fomentar essa visão nos educandos. E que os cursos de design devem incentivar a pratica dos professores considerando a empatia e o respeito mutuo. Para além dessa relação é importante o conhecimento mínimo da área de saber do outro professor colaborador, assim como, a sua importância, para criar uma sinergia entre as disciplinas de requisitos paralelos. A interdisciplinaridade não é uma pratica que deva ser imposta e sim uma ação voluntária com base na empatia e sinergia dos professores envolvidos. Uma imposiçáo pode provocar um fracasso da pratica $\mathrm{da}$ interdisciplinaridade tanto entre os professores, os alunos e nos resultados dos projetos.

\section{Referências}

ASCENCIO, Ana Fernanda Gomes e Campos; VENERUCHI, Edilene Aparecida. (2012). Fundamentos da programação de computadores. 3ed. Pearson.

BEORKREM, C. (2012). Material Strategies in Digital Fabrication. London: Routledge.

CRAIG, John J. (2012). Robótica. 3ed. Pearson..

FAZENDA, Ivani Catarina Arantes. (1979) Integração e interdisciplinaridade no ensino brasileiro. Ediçôes Loyola. . (1996). Práticas interdisciplinares na Escola. São Paulo: Cortez.

LINS, Sérgio. (2003). Transferindo conhecimento tácito: Uma abordagem construtivista. Rio de Janeiro: E-papers Serviços Editoriais.

LIOU, F. (2008).Rapid Prototyping and Engineering Applications: A Toolbox for Prototype Development. N.Y: Taylor and Francis. MCROBERTS, Michael. (2011). ArduinoBásico, Novatec.

MITCHELL, W.; Mccullough M. (1994).Digital Design Media.N. York: Van NostrandReinhold.

PAZMINO, Ana Veronica. (2013). Como se cria: 40 métodos de design de produtos. Ed. Blucher. São Paulo.

SCHODEK, D. et al. (2005). Digital Design and Manufacturing. New Jersey: John Wiley and sons.

SHÖN, Donald A. (2000). Educando o profissional reflexivo: um novo design para o ensino e a aprendizagem. Artmed. Porto Alegre.

TRONCA, D.(2006) Transdisciplinaridade em Edgar Morin. Caxias do Sul. RS.

VERGANTI, Roberto. (2012). Design-DrivenInnovation. Mudando as regras da competição: A inovaçáo radical do significado de produtos. São Paulo: Editora Canal Certo.

VOLPATO, Neri. (2007).Prototipagem Rápida - Tecnologia e aplicaçóes. São Paulo: Edgard Blucher. 